\title{
1 Predictors of antidepressant use in the English 2 population: analysis of the Adult Psychiatric Morbidity Survey
}

\author{
4 S. Boyle ${ }^{1, *}$, J. Murphy ${ }^{1}$, M. Rosato ${ }^{2}$, D. Boduszek ${ }^{3}$ and M. Shevlin ${ }^{1}$ \\ $5{ }^{1}$ School of Psychology and Psychology Research Institute, Ulster University, Londonderry, UK \\ ${ }^{2}$ Bamford Centre for Mental Health and Wellbeing, Ulster University, Londonderry, UK \\ ${ }^{3}$ School of Human and Health Sciences, University of Huddersfield, Huddersfield, UK
}

\begin{abstract}
Objectives. The rate of antidepressant use in the United Kingdom has outpaced diagnostic increases in the prevalence of depression. Research has suggested that personal and socioeconomic risk factors may be contributing to antidepressant use. To date, few studies have addressed these possible contributions. Thus, this study aimed to assess the relative strength of personal, socioeconomic and trauma-related risk factors in predicting antidepressant use.
\end{abstract}

Methods. Data were derived from the Adult Psychiatric Morbidity Survey $(n=7403)$, a nationally representative household sample of adults residing in England in 2007. A multivariate binary logistic regression model was developed to assess the associations between personal, socioeconomic and trauma-related risk factors and current antidepressant use.

Results. The strongest predictor of current antidepressant use was meeting the criteria for an ICD-10 depressive episode [odds ratio $(\mathrm{OR})=9.04$ ]. Other significant predictors of antidepressant use in this analysis included English as first language $(\mathrm{OR}=3.45)$, female gender $(\mathrm{OR}=1.98)$, unemployment $(\mathrm{OR}=1.82)$ and childhood sexual abuse $(\mathrm{OR}=1.53)$.

Conclusions. Several personal, socioeconomic and trauma-related factors significantly contributed to antidepressant use in the multivariate model specified. These findings aid our understanding of the broader context of antidepressant use in the United Kingdom.

Received 24 January 2018; Revised 4 April 2018; Accepted 6 April 2018

Key words: Antidepressants, depression, epidemiology, regression analysis, United Kingdom.

Rates of antidepressant use in the United Kingdom are amongst the highest in Europe (McClure, 2014) and are continually increasing; recent health statistics published by the Organisation for Economic Co-operation and Development (OECD, 2017) indicate that in 2015, the estimated daily dosage of antidepressants was $94.2 / 1000$ people in the United Kingdom, approximately double the estimated daily dosage in 2005 (47.3/ 1000). Whilst antidepressant use has increased, the prevalence of depression has not increased significantly (Baxter et al. 2014). According to estimates from the most recent edition of the Adult Psychiatric Morbidity Survey (APMS) the prevalence of depression in England has increased by 1\% between 2007 and 2014 (McManus et al. 2016). In addition, epidemiological evidence suggests that any increases observed in prevalence rates of depression can be explained by population growth and changing age structures (Baxter et al. 2014). The reasons

* Address for correspondence: S. Boyle, School of Psychology and Psychology Research Institute, Ulster University, Magee Campus, Northland Road, Londonderry BT48 7JL, Northern Ireland, UK.

(Email: s.boyle@ulster.ac.uk) behind this disparity between the prevalence of depression and rates of antidepressant use remain unclear (Munoz-Arroyo et al. 2006). Depression irrefutably remains a strong predictor of antidepressant use; results from the European Study of the Epidemiology of Mental Disorders indicated that a diagnosis of depression increases the probability of antidepressant use fivefold (Demyttenaere et al. 2008). However, the disparity between antidepressant prescribing rates and rates of depression suggests that depression is only one of many potential risk factors for antidepressant use (Demyttenaere et al. 2008). Research has now focused on a range of personal, physical health, socioeconomic and traumarelated factors in predicting antidepressant use (Demyttenaere et al. 2008; Butterworth et al. 2013; Lewer et al. 2015).

The small numbers of studies that have addressed antidepressant use in the general population have reported that age and gender are strong predictors (Demyttenaere et al. 2008; Lewer et al. 2015); the risk for antidepressant use generally increases from young adulthood to middle adulthood [odds ratio $(\mathrm{OR})=$ 1.69], and declines in older adulthood $(\mathrm{OR}=1.45)$ 
(Lewer et al. 2015). In addition, epidemiological evidence has shown that being female is associated with an approximate $80 \%$ increase in risk for antidepressant use (Benson et al. 2015). This is expected given that patterns of antidepressant use tend to follow those for diagnosis of major depressive disorder (MDD), and epidemiological research has reported that middle age and female gender are significant risk factors for MDD (Kessler et al. 2003; Hasin et al. 2005; Seedat et al. 2009). Social isolation has also been linked with antidepressant use. Previous research has shown that loneliness increases the risk of using any psychotropic medication (including antidepressants) in older adults by about $50 \%$ (Boehlen et al. 2015). Moreover, there is evidence that increases in rates of antidepressant use may be a consequence of living alone. In an analysis of the Health 2000 study it was reported that those of working age who lived alone had an 80\% higher risk of antidepressant use during the 7-year follow-up period (Pulkki-Råback et al. 2012). There is relatively little research on antidepressant use by migrants. A possible explanation is that only a small proportion $(32 \%)$ of new migrants to the UK register with a GP (Stagg et al. 2012). Moreover, the Office for National Statistics has reported that the top-10 countries of birth for non-UK migrants in 2015 included countries such as India, Pakistan and China (Office for National Statistics, 2016). Previous analyses of the perceptions of mental illness in India for example, have shown that depression is less often perceived as a mental disorder than other more serious disorders such as the psychoses (Wig et al. 1980). As such, the medical approach to treatment is less popular than social or more traditional healing methods (Wig et al. 1980). Thus, it appears that migrants may be less likely to use antidepressants as they are (1) less likely to register with a GP, and consequently are (2) less likely to be diagnosed with depression and (3) may have cultural beliefs about mental health and it's care that is inconsistent with antidepressant use (Wig et al. 1980; Furnham \& Malik, 1994; Stagg et al. 2012).

Prescriptions for antidepressants are increasingly common for people managing chronic physical health conditions, such as fibromyalgia and diabetes (Mojtabai \& Olfson, 2011; Mercier et al. 2013). Whilst there is evidence that the prevalence of antidepressant use is higher in those who have chronic physical conditions, there is little significant evidence for chronic physical conditions as predictors of antidepressant use (Demyttenaere et al. 2008). This may be due in part to there being little in the way of a theoretical framework for understanding the association between physical health and antidepressant use. If we look to the relationship between depression and physical health for more information, research points to the role of the functional impairment (Zeiss et al. 1996). According to the Integrative Model of Depression, poor physical health (without functional impairment) is not a significant predictor of depression (Lewinsohn et al. 1985). This suggests that evaluating physical health-related functional impairment (PHFI) as a predictor of antidepressant use, rather than the presence of any one chronic physical condition, would be prudent.

Socioeconomic disadvantage has long been recognized as a risk factor for depression (Lorant et al. 2003), and more recently recognized as a risk factor for antidepressant use (Butterworth et al. 2013). Butterworth et al. (2013) reported that unemployment significantly increased risk of antidepressant use by more than 2.5 times $(\mathrm{OR}=2.67)$ and those who had experienced financial hardship in the previous year were almost three times as likely $(\mathrm{OR}=2.87)$ to be using antidepressants than those who had not. Indeed, all social disadvantage factors were reported to increase the likelihood of antidepressant use, although two factors (rental housing tenure and not finishing high school) failed to reach statistical significance (Butterworth et al. 2013). These findings suggest that socioeconomic disadvantage is a robust predictor of antidepressant use, however, further evidence is required to assess the unique contributions of socioeconomic disadvantage factors to antidepressant use in a multivariate context, as only financial hardship remained an independent predictor of antidepressant use when depression was controlled for $(\mathrm{OR}=1.43)$.

There is limited research regarding the role of trauma exposure in antidepressant use. A small number of studies have reported significant associations between antidepressant use and stressful life events (SLE) such as bereavement (Maguire et al. 2017) and divorce (Monden et al. 2015). However, there is little research addressing cumulative lifetime stress. There is also a dearth of research regarding the predictive power of traumatic experiences and antidepressant use. Nevertheless, the literature regarding these risk factors and depression provides an indication of the nature of these associations. Depression has been consistently associated with victimizing experiences such as domestic abuse (Campbell et al. 1995) and homelessness (DeForge et al. 2008). It is pertinent to address these relationships between trauma factors and antidepressant use further; previous research addressing the high levels of antidepressant use amongst those reporting traumatic experiences, for example, childhood sexual abuse (CSA), has shown that it can be problematic (Anda et al. 2007; Williams et al. 2016). According to Anda et al. (2007) those who had scored highly on a measure of childhood adversity were three times more likely to have been using antidepressants than those who reported no negative childhood 
experiences. However, adverse childhood experiences are associated with decreases in antidepressant response and remission, in addition to high rates of adverse effects (Williams et al. 2016).

The aim of this study was to assess the relative strength of a range of personal, socioeconomic and trauma-related factors in predicting antidepressant use in the UK population. Evidence has indicated that these factors vary in their strength of association. In order of effect size, previous research has shown that a diagnosis of depression ( $\mathrm{OR}=5.00$ : Demyttenaere $\mathrm{et} \mathrm{al}$. 2008), financial hardship $(\mathrm{OR}=2.87$ : Butterworth et al. 2013), unemployment $(\mathrm{OR}=2.67$ : Butterworth et al. 2013) and female gender $(\mathrm{OR}=1.80$ : Benson et al. 2015) all significantly predict antidepressant use. It has also been demonstrated that age is a significant but non-linear predictor of antidepressant use, with its strength peaking in middle adulthood $(\mathrm{OR}=1.69)$ and decreasing into older adulthood ( $\mathrm{OR}=1.45$ : Lewer $\mathrm{et} \mathrm{al}$. 2015). Two indicators of socioeconomic disadvantage (rental housing tenure and low/no educational qualifications) have shown increased risk for antidepressant use, but these have not reached significance (Butterworth et al. 2013). These factors have nevertheless been included in the investigation as it is difficult to separate the unique effects of highly correlated risk factors such as these. The relative strength of other factors (social isolation, migrant status, PHFI, SLE, victimization and CSA) in predicting antidepressant use in the population is currently unknown. It was hypothesized that each personal (depression, age, gender, social isolation, migrant status and PHFI), socioeconomic disadvantage (employment, housing tenure, educational qualifications and financial hardship) and trauma-related (SLE, victimization and CSA) risk factor would be independently associated with antidepressant use. It was also pertinent to examine these associations in a multivariate context to ascertain the individual contributions of each predictor to antidepressant use when other factors were considered. It was expected that each predictor would significantly contribute to the multivariate model developed for predicting antidepressant use.

\section{Methods}

\section{Participants and study measures}

The data utilized in the current study were derived from the APMS conducted in 2007, a representative sample of the population living in private households in England (McManus et al. 2009). Using the small-users postcode address file, the National Centre for Social Research adopted a multi-stage stratified probabilitysampling design. The survey consisted of a phase 1 and a phase 2 (clinical) interview. For phase 1 of the survey
13214 potentially eligible private households were identified. One adult aged 16 years or over from each household was selected for interview using the Kish grid method (Kish, 1965). To ensure that the results were nationally representative, the data were weighted to account for non-response, gender, age and region. Comprehensive details of the survey methods can be found in the APMS report appendices (McManus et al. 2009). In total, $57 \%$ of those eligible agreed to be interviewed for the APMS, resulting in 7403 successful interviews (3197 males and 4206 females). The sample had a mean age of 51.12 years (S.D. $=18.59$ ). The measures utilized in this analysis were based on questions asked in the APMS 2007 phase 1 questionnaire.

\section{Depression}

A single categorical variable was generated to reflect the severity of depressive symptoms. First, respondents were presented with two screening questions asking whether they had been 'feeling sad, miserable or depressed' $(1=$ yes $/ 0=$ no) or ' (unable) to enjoy or take an interest in things' $(1=$ yes $/ 0=$ no $)$ in the past month. These questions were common to both the fifth edition of the Diagnostic and Statistical Manual of Mental Disorders (DSM-5; American Psychiatric Association, 2013) and the tenth edition of the International Classification of Diseases (ICD-10; World Health Organisation, 1993). Second, the APMS used the Clinical Interview Schedule Revised (CIS-R; Lewis \& Pelosi, 1990), a structured clinical interview, to generate a diagnosis of an ICD-10 2-week depressive episode $(1=$ yes $/ 0=$ no). The resulting variable grouped respondents as: 'no' to both screening instruments, and 'no' to diagnosis of a depressive episode (0), 'yes' to one of the two screening instruments (1), 'yes' to both (2) or met the criteria for diagnosis of a depressive episode (3), which superseded responding 'yes' to either/ both screening instrument(s). Previous analysis of the concurrence of the CIS-R with other diagnostic tools has indicated that in relation to the Schedules for Clinical Assessment in Neuropsychiatry (SCAN), the CIS-R has low sensitivity and high specificity for ICD-10 depressive disorders (Jordanova et al. 2004). Thus, the development of a combined sub-clinical and clinical variable was necessary to increase the range of depression severity measured.

\section{Demographics}

Participants were asked about age, gender, social isolation and migrant status. Age was grouped into four age bands: $16-29$ years; $30-44 ; 45-59$ and 60 or more years. Gender was classified as either male/female (0/1). Household size was represented as living alone $(1=$ yes $/ 0=$ no $)$ and used as an indicator of social 
isolation. First language was summarized as English/not English $(1 / 0)$ and used as a proxy for migrant status.

\section{Physical health-related functional impairment (PHFI)}

This was measured using two items from the Short Form-12 (Ware et al. 1996). Respondents were asked whether, in the past 4 weeks, they had (a) accomplished less work or daily activities due to physical health problems, and whether (b) they were limited in the type of work or daily activities they could do due to physical health problems. Responses were coded as yes (1) or no (0) and summarized as a single physical health indicator $(0=$ no limitation, $1=$ one limitation noted and $2=$ both limitations noted).

\section{Socioeconomic disadvantage}

Employment, housing tenure, educational qualifications and financial hardship (debt and borrowing) were used as indicators of individual-level socioeconomic disadvantage. Respondents were asked whether they were or were not in paid employment during the week preceding the interview. A dichotomous variable based on this question was then derived which classified respondents as unemployed (1) or employed (0). Tenure was summarized as those in owner-occupation (0) and those who in rented accommodation (1). Education was assessed in the survey as qualifications attained ranging from none to degree level and above, and was summarized as no qualifications attained (1) or some qualifications attained (0). Next, two variables - debt and borrowing - described respondents' experience of financial hardship. Respondents were asked whether, in the past year, had they been seriously behind time in paying each of 14 listed financial obligations (e.g. water bill, mortgage repayment, child support). Each response was coded as (yes/ no: $1 / 0)$, and accumulated into a single index reflecting the difficulty the respondent had with debt in the previous year. Respondents were then asked whether during the previous year they had to borrow money to pay for day-to-day needs from four potential sources (pawnbroker, money lender, bank or friends/family). Responses were coded as (yes/no: 1/0) and accumulated into a single variable. For both indices higher scores indicate higher levels of debt or borrowing during the previous year.

\section{Trauma}

Experience of three categories of trauma represented lifetime experience of traumatic events for the participants: SLE, victimization and CSA. Experiences of SLE, such as serious illness, bereavement and being made redundant from work were measured using 11 items derived from the List of Threatening Experiences (LTE) as indicators (Brugha et al. 1985). For this analysis, each LTE item was scored to assess having experienced (1) or not having experienced (0) the event and aggregated into a single index with a range of $0-11$. Moreover, participants were asked about lifetime experience of victimization. Each of seven items (bullying, violence at work, violence in the home, sexual abuse, expulsion from school, running away from home, homelessness) was scored representing the presence/absence $(1 / 0)$ of each type of victimization. These were then summed to provide a total victimization score. Higher scores reflect more types of victimization experienced. Regarding CSA, participants were informed that this section of the interview could potentially cause emotional upset, and that all answers would be confidential. It was also selfcompleted on the computer so the interviewer could not see the responses. Respondents were asked whether, before the age of 16: (a) anyone had talked to them in a sexual way; (b) anyone touched them in a sexual way without consent; or (c) engaged them in sexual intercourse without consent. These three questions were each coded as binary $(1=$ yes, $0=$ no), and then transformed into a single binary variable representing experience of any type of CSA ( $1=$ any CSA; $0=$ no CSA).

\section{Antidepressant use}

Respondents were asked whether they were currently taking any of the following 13 antidepressant medications (Prozac, Lustral, Seroxat, Effexor, Nardil, Manerix, Tryptizol, Tofranil, Anafranil, Prothiaden, Sinequan, Cipramil, Zispen). If yes, they were asked to show the interviewer the medication package. Producing the wrong medication package resulted in exclusion from that particular medication. From this a binary variable was derived classifying respondents as taking no antidepressants (0), or one or more (1).

\section{Analysis strategy}

A multivariate binary logistic regression model was specified and tested using SPSS 24 to assess the impact of predictor variables on the likelihood that respondents were currently using an antidepressant. It was expected that the 14 predictors of antidepressant use would produce a statistically significant model. For each predictor, there was $\leq 1.5 \%$ of missing data due to participants identifying items as not applicable, answering 'don't know' or refusing to answer. The missing data were missing completely at random (Little's MCAR test: $\chi^{2}=20.789, \mathrm{df}=14, p=0.187$ ) and handled using listwise deletion. Predictors were included in the model simultaneously. $\chi^{2}$ Tests were used to assess the goodness of model fit. 


\section{Results}

There were 417 (5.6\%) participants who reported current use of antidepressants in the cohort and the cross-tabulations with the predictor variables are reported in Table 1.

Mean scores on cumulative predictors for those currently taking/not taking antidepressants are presented in Table 2. On financial hardship (debt and borrowing) and trauma (SLE and victimization) indicators, mean scores were consistently higher in the current antidepressant use group. For debt, borrowing and victimization, the mean scores of the current antidepressant use group were more than twice those of the no current antidepressant use group.

As shown in Table 3, all bivariate associations were statistically significant. Larger effects were observed for depression, CSA and English as first language. The weakest effects were observed for living alone and having no qualifications.

Table 3 shows the estimates from the multivariate logistic regression model where all predictor variables were entered into the model with current antidepressant use as the dependent variable. The overall model

Table 1. Counts and percentages for current antidepressant use and risk factors

\begin{tabular}{lcc}
\hline Predictor & $\begin{array}{l}\text { No current ADM use } \\
(n=6971)\end{array}$ & $\begin{array}{l}\text { Current ADM use } \\
(n=417)\end{array}$ \\
\hline Depression & & $92(22.1 \%)$ \\
$\quad$ None & $3947(56.6 \%)$ & $154(36.9 \%)$ \\
Either screener & $2216(31.8 \%)$ & $171(41.0 \%)$ \\
Both screeners & $807(11.6 \%)$ & \\
Age & & $36(8.6 \%)$ \\
$16-29$ & $1012(14.5 \%)$ & $127(30.5 \%)$ \\
$30-44$ & $1837(26.4 \%)$ & $145(34.8 \%)$ \\
$45-59$ & $1601(23.0 \%)$ & $109(26.1 \%)$ \\
$60+$ & $2521(36.2 \%)$ & $307(73.6 \%)$ \\
Female & $3886(55.7 \%)$ & $147(35.3 \%)$ \\
Living alone & $1940(27.8 \%)$ & $408(97.8 \%)$ \\
English as first & $6563(94.4 \%)$ & \\
language & & $214(51.3 \%)$ \\
PHFI & & $46(11.1 \%)$ \\
None & $5325(75.1 \%)$ & $157(37.6 \%)$ \\
Either indicator & $549(7.9 \%)$ & $273(65.9 \%)$ \\
Both indicators & $1187(17.0 \%)$ & $181(43.8 \%)$ \\
Unemployed & $3310(47.8 \%)$ & $139(33.6 \%)$ \\
Renting home & $1961(28.4 \%)$ & $(29.9 \%)$ \\
No qualifications & $1966(28.4 \%)$ & \\
CSA & $861(12.5 \%)$ & \\
\hline & &
\end{tabular}

ADM, antidepressant medication; PHFI, physical healthrelated functional impairment; CSA, childhood sexual abuse.

Pearson's $\chi^{2}$ tests for antidepressant use and all risk factors reached statistical significance $(p<0.001)$. was statistically significant $\left(\chi^{2}(19)=522.76, p<0.001\right)$ and explained between $7 \%$ (Cox and Snell's $\mathrm{R}^{2}$ ) and $20 \%$ (Nagelkerke's $R^{2}$ ) of the variance in current

Table 2. Comparison of means and standard deviations of scores on cumulative risk factors between those currently taking or not taking antidepressants

\begin{tabular}{lll}
\hline & $\begin{array}{l}\text { No current ADM use } \\
{[\text { mean (s.D.) }}\end{array}$ & $\begin{array}{l}\text { Current ADM use } \\
{[\text { mean (s.D.)] }}\end{array}$ \\
\hline Debt & $0.17(0.77)$ & $0.47(1.27)$ \\
Borrowing & $0.09(0.35)$ & $0.24(0.60)$ \\
SLE & $3.11(1.94)$ & $3.98(2.07)$ \\
Victimization & $0.43(0.83)$ & $1.05(1.31)$ \\
\hline
\end{tabular}

ADM, antidepressant medication; SLE, stressful life events. Independent samples t-tests for antidepressant use and all risk factors reached statistical significance $(p<0.01)$.

Table 3. Bivariate and multivariate odds ratios (OR) from binary logistic regression analyses of current antidepressant use and risk factors

\begin{tabular}{|c|c|c|c|c|}
\hline & \multicolumn{4}{|c|}{ Current ADM use } \\
\hline & \multicolumn{2}{|c|}{ Bivariate } & \multicolumn{2}{|c|}{ Multivariate } \\
\hline & OR & $95 \% \mathrm{CI}$ & OR & $95 \% \mathrm{CI}$ \\
\hline \multicolumn{5}{|c|}{ Depression (ref = none) } \\
\hline Either screener & $2.77^{* * *}$ & $2.18-3.62$ & $2.13^{* * *}$ & $1.61-2.81$ \\
\hline Both screeners & $6.81^{* * *}$ & $5.12-9.10$ & $3.85^{* * *}$ & $2.81-5.26$ \\
\hline $\begin{array}{l}\text { ICD-10 depressive } \\
\text { episode }\end{array}$ & $22.55^{* * *}$ & $15.83-32.12$ & $9.04^{* * *}$ & $6.01-13.60$ \\
\hline \multicolumn{5}{|l|}{ Age $($ ref $=60+)$} \\
\hline $16-29$ & 0.82 & $0.56-1.21$ & 0.81 & $0.49-1.32$ \\
\hline $30-44$ & $1.60^{* * *}$ & $1.23-2.08$ & $1.84^{* *}$ & $1.29-2.64$ \\
\hline $45-59$ & $2.10^{* * *}$ & $1.62-2.71$ & $1.97^{* * *}$ & $1.43-2.72$ \\
\hline Female & $2.22^{* * *}$ & $1.77-2.77$ & $1.96^{* * *}$ & $1.53-2.51$ \\
\hline Living alone & $1.41^{* *}$ & $1.14-1.74$ & 1.06 & $0.82-1.36$ \\
\hline $\begin{array}{l}\text { First language is } \\
\text { English }\end{array}$ & $2.82^{* *}$ & $1.45-5.50$ & $3.48^{* *}$ & $1.51-8.02$ \\
\hline \multicolumn{5}{|l|}{ PHFI (ref = none) } \\
\hline Either indicator & $2.05^{* * *}$ & $1.47-2.85$ & $1.52^{*}$ & $1.05-2.18$ \\
\hline Both indicators & $3.24^{* * *}$ & $2.61-4.01$ & $1.57^{* *}$ & $1.22-2.04$ \\
\hline Unemployed & $2.12^{* * *}$ & $1.72-2.61$ & $1.82^{* * *}$ & $1.40-2.38$ \\
\hline Renting home & $1.97^{* * *}$ & $1.61-2.41$ & 1.22 & $0.95-1.58$ \\
\hline No qualifications & $1.28^{*}$ & $1.03-1.57$ & 1.01 & $0.78-1.32$ \\
\hline Debt & $1.30^{* * *}$ & $1.21-1.41$ & 1.01 & $0.90-1.13$ \\
\hline Borrowing & $2.00^{* * *}$ & $1.67-2.39$ & 1.15 & $0.89-1.48$ \\
\hline SLE & $1.23^{* * *}$ & $1.17-1.28$ & 1.07 & $1.00-1.13$ \\
\hline Victimization & $1.68^{* * *}$ & $1.55-1.81$ & $1.18^{* *}$ & $1.06-1.32$ \\
\hline CSA & $2.98^{* * *}$ & $2.38-3.73$ & $1.53^{* *}$ & $1.16-2.00$ \\
\hline
\end{tabular}

ADM, antidepressant medication; $\mathrm{CI}$, confidence interval; PHFI, physical health-related functional impairment; SLE, stressful life events; CSA, childhood sexual abuse. ${ }^{*} p<0.05,{ }^{* *} p<0.01,{ }^{* * *} p<0.001$. 
antidepressant use. Seven of the predictors did not make a statistically significant contribution to the model: age 16-30, living alone, renting home, no qualifications, debt, borrowing and SLE. All other variables remained statistically significant. Overall, the strongest predictor of current antidepressant use was an ICD-10 depressive episode $[\mathrm{OR}=9.04$; confidence intervals $(\mathrm{CI})=6.01-$ 13.60], followed by saying yes to both screeners of depression $(\mathrm{OR}=3.85 ; \mathrm{CI}=2.81-5.26)$ and English as first language $(\mathrm{OR}=3.48 ; \mathrm{CI}=1.51-8.02)$. Use was higher in females than males $(\mathrm{OR}=1.96$; $\mathrm{CI}=1.53$ 2.51 ), and risk of use for those who were middle-aged was double that of those aged 60 or more $(\mathrm{OR}=1.97$; $\mathrm{CI}=1.43-2.72$ ). Reporting experience of CSA was associated with an approximate $50 \%$ increased risk for antidepressant use.

\section{Discussion}

The current study utilized data from the APMS to assess a range of important personal, socioeconomic disadvantage and trauma-related predictors for current antidepressant use. The results supported the primary hypothesis. The 14 predictors of antidepressant use were all individually significantly associated with antidepressant use. With regards to the second hypothesis, several of factors that have been investigated previously (depression, middle-age and female gender) individually and significantly contributed to antidepressant use in the multivariate model. These results were consistent with previous research findings (Demyttenaere et al. 2008; Butterworth et al. 2013; Lewer et al. 2015). In this analysis there were increased odds of antidepressant use in the two middle-adulthood groups, and membership of the youngest age group did not significantly increase odds of antidepressant use in comparison to the oldest age group. An explanation for this may be that antidepressant use rises and falls with the lifetime prevalence of depression, which increases into middle adulthood before dropping in older adulthood (Kessler et al. 2003). Moreover, of the previously investigated socioeconomic disadvantage indicators, only unemployment significantly independently contributed to the multivariate model. In this analysis unemployment actually performed better than it did in an analysis by Butterworth et al. (2013), as it remained a significant predictor of antidepressant use in a model including depression (Butterworth et al. 2013). With regards to the other four socioeconomic disadvantaged indicators (renting home, no qualifications, debt and borrowing) the results indicated that they failed to independently contribute to the multivariate model. These mixed results for indicators of socioeconomic disadvantage as predictors of antidepressant use add to an already inconclusive evidence base (Demyttenaere et al. 2008; Butterworth et al. 2013; Lewer et al. 2015) and highlight the need for further investigation.

Furthermore, this study used some variables that have not been examined in previous research (living alone, migrant status, PHFI, SLE, victimization and CSA), and of these migrant status (English as first language) was the strongest predictor. PHFI, victimization and CSA were also significant predictors of antidepressant use. However, the hypothesis failed to be supported for social isolation (measured by living alone) and SLE, as they failed to independently and significantly contribute to the model. This is surprising as they are both predictors of general psychopathology (Molnar et al. 2001; Joutsenniemi et al. 2006), and as living alone has previously predicted antidepressant use in a working-age population (Pulkki-Råback et al. 2012).

This analysis indicated that even when depressive symptoms are controlled for, those experiencing poor social and economic circumstances are more likely to be prescribed antidepressant medications. As such, it is believed that this analysis adds to the long-term documentation of the failure of our services to address the social causes of depression and distress.

The main strengths of this study are that it is based on a large, nationally representative sample, and that the APMS 2007 survey methods are stringent (McManus et al. 2009). In addition, participants in the APMS 2007 were required to show medication packages when reporting which antidepressants they used, arguably a more objective mechanism than recall alone. However, there are limitations associated with this study. First, this was a study of individual-level predictors. It did not take into account broader societal factors, such as reductions in the stigma associated with mental health and its treatment (Angermeyer et al. 2017). Next, there can be issues with analyses based on individual-level self-report data. Whilst self-report data are less problematic for factors such as demographics, it may have repercussions for other indicators in this study. Evaluating trauma experienced over the lifetime is complex, involving issues with validity of reports and issues of definition (Goodman et al. 1998). Yet, whilst the reliability and validity of self-reported trauma in this study cannot be definitively established, evidence suggests these accounts are reliable in population and clinical samples (Fisher et al. 2011). Moreover, this analysis was limited to using first language and living alone as proxies for migrant status and social isolation respectively. Where possible more direct indicators should be utilized, for example UCLA Loneliness Scale (Russell et al. 1978).

Diagnosis of an ICD-10 depressive episode was the strongest predictor of antidepressant use in this 
multivariate analysis. This result is in agreement with previous literature, but the OR (9.04) was higher than that recorded in previous work $(\mathrm{OR}=5.00$ : Demyttenaere et al. 2008). This is probably due to differences in the operationalization of depression between studies. This study utilized a combined variable with ICD-10 depressive episode measured using the CIS-R. Previous works have utilized 12-month prevalence of depression measured using the Composite International Diagnostic Interview (Demyttenaere et al. 2008), and 4-week prevalence using the Mental Health Inventory-5 (Lewer et al. 2015). Further work is required to ascertain a consensus.

Furthermore, it must be taken into consideration that this survey was completed on private households only. Research has shown that there are high, often inappropriate rates of antidepressant prescribing to the elderly in residing in care homes (Read et al. 2016). Our finding that risk of antidepressant use is highest in middle-age must be interpreted with this in mind.

In conclusion, using a large nationally representative data set of adults in England, this study provides evidence of the relative strength of a range of personal, socioeconomic and trauma-related factors in predicting antidepressant use. This study has confirmed that depression, age, gender, English as first language, PHFI, unemployment, victimization and CSA significantly predict antidepressant use. These findings have potentially important clinical implications for service planning of psychosocial services. There has been a reduction in stigma regarding mental health treatment, leading to increased numbers seeking treatment and massive pressures on resources, particularly in primary care services (Angermeyer et al. 2017). Indeed, GPs in the UK have reported that they are prescribing more antidepressants because of poor access to psychosocial services, including long waiting times (Mental Health Foundation, 2005). Thus, identifying these predictors is the first step in identifying those most in need so that psychosocial services can be targeted towards those groups. It is recommended that future work builds upon these findings via the development of 'high-risk' profiles and longitudinal modelling of the effects of these predictors on antidepressant use. Further research is warranted so that the broader context of current antidepressant use in the population can be understood and accounted for.

\section{Financial Support}

This work was supported as part of a wider project by the Economic and Social Research Council (ES/N012216/1).

\section{Conflicts of Interest}

All authors declare that there are no conflicts of interest to disclose.

\section{Ethical Standards}

The authors assert that all procedures contributing to this work comply with the ethical standards of the relevant national and institutional committee on human experimentation with the Helsinki Declaration of 1975, as revised in 2008. Ethical approval for APMS 2007 was obtained from the Royal Free Hospital and Medical School Research Ethics Committee. The anonymised data set used in this analysis was available freely from the UK Data Archive.

\section{References}

American Psychiatric Association (2013). Diagnostic and Statistical Manual of Mental Disorders (DSM-5). American Psychiatric Publishing: Washington, DC.

Anda RF, Brown DW, Felitti VJ, Bremner JD, Dube SR, Giles WH (2007). Adverse childhood experiences and prescribed psychotropic medications in adults. American Journal of Preventative Medicine 32, 389-394.

Angermeyer MC, van der Auwera S, Carta MG, Schomerus G (2017). Public attitudes towards psychiatry and psychiatric treatment at the beginning of the 21st century: a systematic review and meta-analysis of population surveys. World Psychiatry 16, 50-61.

Baxter AJ, Scott KM, Ferrari AJ, Norman RE, Vos T, Whiteford HA (2014). Challenging the myth of an "epidemic" of common mental disorders: trends in the global prevalence of anxiety and depression between 1990 and 2010. Depression and Anxiety 31, 506-516.

Benson T, O'Neill S, Murphy S, Ferry F, Bunting B (2015). Prevalence and predictors of psychotropic medication use: results from the Northern Ireland Study of Health and Stress. Epidemiology and Psychiatric Sciences 24, 542-552.

Boehlen F, Herzog W, Quinzler R, Haefeli WE, Maatouk I, Niehoff D, Saum KU, Brenner H, Wild B (2015). Loneliness in the elderly is associated with the use of psychotropic drugs. International Journal of Geriatric Psychiatry 30, 957-964.

Brugha T, Bebbington P, Tennant C, Hurry J (1985). The list of threatening experiences: a subset of 12 life event categories with considerable long-term contextual threat. Psychological Medicine 15, 189-194.

Butterworth P, Olesen SC, Leach LS (2013). Socioeconomic differences in antidepressant use in the PATH Through Life Study: evidence of health inequalities, prescribing bias, or an effective social safety net? Journal of Affective Disorders 149, 75-83.

Campbell R, Sullivan CM, Davidson WS (1995). Women who use domestic violence shelters changes in depression over time. Psychology of Women Quarterly 19, 237-255.

DeForge BR, Belcher JR, O'Rourke M, Lindsey MA (2008). Personal resources and homelessness in early life: predictors of depression in consumers of homeless multiservice centers. Journal of Loss and Trauma 13, 222-242.
570

571

572

573

574

575 
Demyttenaere K, Bonnewyn A, Bruffaerts R, De Girolamo G, Gasquet I, Kovess V, Haro JM, Alonso J (2008). Clinical factors influencing the prescription of antidepressants and benzodiazepines: results from the European study of the epidemiology of mental disorders (ESEMeD). Journal of Affective Disorders 110, 84-93.

Fisher HL, Craig TK, Fearon P, Morgan K, Dazzan P, Lappin J, Hutchinson G, Doody GA, Jones PB, McGuffin P, Murray RM, Leff J, Morgan C (2011). Reliability and comparability of psychosis patients' retrospective reports of childhood abuse. Schizophrenia Bull 37, 546-553.

Furnham A, Malik R (1994). Cross-cultural beliefs about "depression". International Journal of Social Psychiatry 40, 106-123.

\section{Goodman LA, Corcoran C, Turner K, Yuan N, Green BL} (1998). Assessing traumatic event exposure: general issues and preliminary findings for the Stressful Life Events Screening Questionnaire. Journal of Traumatic Stress 11, 521-542.

Hasin DS, Goodwin RD, Stinson FS, Grant BF (2005). Epidemiology of major depressive disorder: results from the National Epidemiologic Survey on Alcoholism and Related Conditions. Archives of General Psychiatry 62, 1097-1106.

Jordanova V, Wickramesinghe C, Gerada C, Prince M (2004). Validation of two survey diagnostic interviews among primary care attendees: a comparison of CIS-R and CIDI with SCAN ICD-10 diagnostic categories. Psychological Medicine 34, 1013-1024.

Joutsenniemi K, Martelin T, Martikainen P, Pirkola S, Koskinen S (2006). Living arrangements and mental health in Finland. Journal of Epidemiology \& Community Health 60, 468-475.

Kessler RC, Berglund P, Demler O, Jin R, Koretz D, Merikangas KR, Rush AJ, Walters EE, Wang PS (2003). The epidemiology of major depressive disorder: results from the National Comorbidity Survey Replication (NCS-R). JAMA 289, 3095-3105.

Kish L (1965). Survey Sampling. Wiley: New York. Lewer D, O'Reilly C, Mojtabai R, Evans-Lacko S (2015). Antidepressant use in 27 European countries: associations with sociodemographic, cultural and economic factors. British Journal of Psychiatry 207, 221-226.

Lewinsohn PM, Hoberman H, Teri L, Hautzinger M (1985). An integrative theory of depression. In Theoretical Issues in Behavior Therapy (ed. R. Reiss and R. Bootzin), pp. 331-359. Academic Press: New York.

Lewis G, Pelosi AJ (1990). Manual of the Revised Clinical Interview Schedule (CIS-R). Institute of Psychiatry: London.

Lorant V, Deliège D, Eaton W, Robert A, Philippot P, Ansseau $M$ (2003). Socioeconomic inequalities in depression: a meta-analysis. American Journal of Epidemiology 157, 98-112.

Maguire A, Moriarty J, O'Reilly D, McCann M (2017). Education as a predictor of antidepressant and anxiolytic medication use after bereavement: a population based record linkage study. Quality of Life Research 26, 1251-1262. McClure I (2014). The Script Report (http:/ / www.thedetail.tv/ articles/new-data-shows-northern-ireland-is-a-world-leaderin-prescription-drug-use). Accessed 5 December 2017.
McManus S, Bebbington P, Jenkins R, Brugha T (2016). Mental Health and Wellbeing in England: Adult Psychiatric Morbidity Survey 2014. NHS Digital: Leeds.

McManus S, Meltzer H, Brugha TS, Bebbington PE, Jenkins R (2009). Adult Psychiatric Morbidity in England, 2007: Results of a Household Survey. The NHS Information Centre for Health and Social Care: UK.

Mental Health Foundation (2005). Up and Running? Exercise Therapy and the Treatment of Mild or Moderate Depression in Primary Care. Mental Health Foundation: London.

Mercier A, Auger-Aubin I, Lebeau JP, Schuers M, Boulet P, Hermil JL, Van Royen P, Peremans L (2013). Evidence of prescription of antidepressants for non-psychiatric conditions in primary care: an analysis of guidelines and systematic reviews. BMC Family Practice 14, 55. https:/ / doi. org/10.1186/1471-2296-14-55.

Mojtabai R, Olfson M (2011). Proportion of antidepressants prescribed without a psychiatric diagnosis is growing. Health Affairs 30, 1434-1442.

Molnar BE, Buka SL, Kessler RC (2001). Child sexual abuse and subsequent psychopathology: results from the National Comorbidity Survey. American Journal of Public Health 91, 753-760.

Monden CW, Metsä-Simola N, Saarioja S, Martikainen P (2015). Divorce and subsequent increase in uptake of antidepressant medication: a Finnish registry based study on couple versus individual effects. BMC Public Health 15, 158.

Munoz-Arroyo R, Sutton M, Morrison J (2006). Exploring potential explanations for the increase in antidepressant prescribing in Scotland using secondary analyses of routine data. British Journal of General Practice 56, 423-428.

Office for National Statistics (2016). Population of the United Kingdom by country of birth and nationality 2015 [dataset] (https://www.ons.gov.uk/peoplepopulationand community/populationandmigration/international migration/datasets/populationoftheunitedkingdomby countryofbirthandnationality). Accessed 5 December 2017.

Organisation for Economic Co-operation and Development (2017). Health at a Glance: 2017. Organisation for Economic Co-operation and Development Publishing: Paris.

Pulkki-Råback L, Kivimäki M, Ahola K, Joutsenniemi K, Elovainio M, Rossi H, Puttonen S, Koskinen S, Isometsä E, Lönnqvist J, Virtanen M (2012). Living alone and antidepressant medication use: a prospective study in a working-age population. BMC Public Health 12, 236. https://doi.org/10.1186/1471-2458-12-236.

Read J, Gibson KL, Cartwright C (2016). Are older people prescribed antidepressants on the basis of fewer symptoms of depression, and for longer periods of time? A survey of 1825 New Zealanders. Australasian Journal of Ageing 35, 193-197.

Russell D, Peplau LA, Ferguson ML (1978). Developing a measure of loneliness. Journal of Personality Assessment 42, 290-294.

Seedat S, Scott KM, Angermeyer MC, Berglund P, Bromet EJ, Brugha TS, Demyttenaere K, De Girolamo G, Haro JM, Jin R, Karam EG (2009). Cross-national associations between gender and mental disorders in the World Health Organization World Mental Health Surveys. Archives of General Psychiatry 66, 785-795. 
Stagg HR, Jones J, Bickler G, Abubakar I (2012). Poor uptake of primary healthcare registration among recent entrants to the UK: a retrospective cohort study. BMJ Open 2, e001453. http:/ /dx.doi.org/10.1136/bmjopen-2012-001453.

Ware JE, Kosinski M, Keller SD (1996). A 12-Item Short-Form Health Survey: construction of scales and preliminary tests of reliability and validity. Medical Care 34, 220-233.

Wig N, Suckman M, Routledge R, Srinvasa Murthy R, Ladrido-Ignacio L, Ibrahim H, Harding T (1980). Community reaction to mental disorders: a key informant study in three developing countries. Acta Psychiatrica Scandinavia 61, 111-126.
Williams LM, Debattista C, Duchemin AM, Schatzberg AF, Nemeroff CB (2016). Childhood trauma predicts antidepressant response in adults with major depression: data from the randomized international study to predict optimized treatment for depression. Translational Psychiatry 6, 799.

World Health Organization (1993). The ICD-10 Classification of Mental and Behavioural Disorders: Diagnostic Criteria for

Research. World Health Organisation: Geneva.

Zeiss AM, Lewinsohn PM, Rohde P, Seeley JR (1996).

Relationship of physical disease and functional impairment to depression in older people. Psychology and Ageing 11, 572-581. 